\title{
Effects of Composites Containing Bioactive Glasses on Demineralized Dentin
}

\author{
A. Tezvergil-Mutluay', R. Seseogullari-Dirihan', V.P. Feitosa ${ }^{2}$, \\ G. Cama ${ }^{3}$, D.S. Brauer ${ }^{4}$, and S. Sauro ${ }^{5,6}$
}

\begin{abstract}
The aim of this study was to evaluate the degradation of completely demineralized dentin specimens in contact with a filler-free or 2 ion-releasing resins containing micrometer-sized particles of Bioglass 45S5 (BAG) or fluoride-containing phosphate-rich bioactive glass (BAG-F). Fourier transform infrared spectroscopy (FTIR) and scanning electron microscopy (SEM) were also used to evaluate the remineralization induced by the experimental ion-releasing resin-based materials. Dentin beams were totally demineralized in $\mathrm{H}_{3} \mathrm{PO}_{4}$ $(10 \%)$ and placed in direct contact with a filler-free (RESIN) or 2 experimental ion-releasing resins (BAG or BAG-F) and immersed in artificial saliva (AS) up to $30 \mathrm{~d}$. Further specimens were also processed and submitted to FTIR and SEM analysis to evaluate the remineralization induced by such ion-releasing resins before and after AS immersion. BAG and BAG-F alkalinized the incubation media. A significant decrease of the dry mass was observed between the specimens of all groups stored for 3 and $30 \mathrm{~d}$ in AS. However, the fluoride-containing phosphate-rich bioactive glass incorporated into a resin-based material (BAG-F) showed greater ability in reducing the solubilization of $C$-terminal cross-linked telopeptide (ICTP) and C-terminal telopeptide (CTX) after prolonged AS storage. Moreover, after $30 \mathrm{~d}$ of AS storage, BAG-F showed the greatest remineralizing effect on the stiffness of the completely demineralized dentin matrices. In conclusion, fluoride-containing phosphate-rich bioactive glass incorporated as micrometer-sized filler in dental composites may offer greater beneficial effects than Bioglass $45 \mathrm{~S} 5$ in reducing the enzyme-mediated degradation and remineralization of demineralized dentin.
\end{abstract}

Keywords: collagen, demineralization, endogenous proteinases, remineralization, matrix metalloproteinases (MMPs), composite materials

\section{Introduction}

Enzymatic degradation of dentin collagen fibrils and hydrolysis of resin polymer matrix represent the main mechanisms responsible for bonding failure over time (Pashley et al. 2011). Preservation of the structural integrity of collagen fibrils is essential for the longevity of the resin-dentin interface, particularly when restorations are performed after selective caries removal (Aguiar et al. 2014; Abuna et al. 2016). Inactive and/ or proform of proteolytic enzymes such as matrix metalloproteinases (MMPs) exist within mineralized dentin (Palosaari et al. 2003). MMPs are exposed and activated when bacteriaderived acids demineralize dentin, as well as when using phosphoric acid etchants or self-etch adhesives (Lehmann et al. 2009). Although a small fraction of such acids (De Munck et al. 2009) may extract these proteases, most remain bonded to the matrix in active forms and hydrolyze C-terminal crosslinked telopeptide (ICTP) (Pashley et al. 2004; DeVito-Moraes et al. 2016). Cathepsin K (CTP) is a further proteolytic enzyme found in active form in demineralized dentin, which hydrolyzes the C-terminal telopeptide (CTX) (Nascimento et al. 2011; Tezvergil-Mutluay et al. 2014).

It has been demonstrated that dentin remineralization may reduce enzymatic-mediated matrix degradation (Osorio et al. 2012; Tezvergil-Mutluay et al. 2014). The rationale is that calcium
$\left(\mathrm{Ca}^{2+}\right)$ and phosphate $\left(\mathrm{PO}_{4}^{3-}\right)$ ions released by bioactive materials may precipitate onto demineralized dentin collagen fibrils and fossilize active endogenous proteases (Tjäderhane et al. 2013). Bioactive glasses are known to form a biomimetic nonstoichiometric nano-crystalline apatite when immersed into physiological solutions (O’Donnell et al. 2009).

'Department of Restorative Dentistry and Cariology, Institute of Dentistry, University of Turku, Turku, Finland, and Turku University Hospital, TYKS, Turku, Finland

${ }^{2}$ Research Division, Paulo Picanço School of Dentistry, Fortaleza, Brazil ${ }^{3}$ Polymer Chemistry \& Biomaterials Group, University of Ghent, Ghent, Belgium

${ }^{4}$ Otto Schott Institute of Materials Research, Friedrich Schiller University Jena, Jena, Germany

${ }^{5}$ Dental Biomaterials, Departamento de Odontología, Facultad de Ciencias de la Salud, University CEU-Cardenal Herrera, Valencia, Spain ${ }^{6}$ Biomaterials, Biophotonics and Tissue Engineering, King's College London Dental Institute (KCLDI), London, UK

\section{Corresponding Author:}

S. Sauro, Dental Biomaterials, Preventive and Minimally Invasive Dentistry, Departamento de Odontología, Facultad de Ciencias de la Salud, Universidad CEU-Cardenal Herrera. C/Del Pozo s/n, Alfara del Patriarca, 46 II 5 Valencia, Spain.

Email: salvatore.sauro@uchceu.es 
Moreover, fluoride has been advocated as a potential inhibitor of cathepsin K and matrix-bound MMPs (Mei et al. 2014), as it was shown to reduce the degradation of dentin matrix (Altinci et al. 2016). However, it is not known whether fluoridecontaining bioactive glass (Groh et al. 2014) can promote dentin remineralization and inhibition of the dentin-matrix degradation.

Thus, this study aimed at evaluating the amount of solubilized CTX and ICTP, as well as the modulus of elasticity of completely demineralized dentin specimens in contact for 3 or $30 \mathrm{~d}$ with a filler-free or 2 ion-releasing resin composites filled with micrometer-sized particles of Bioglass 45S5 or a fluoridecontaining phosphate-rich bioactive glass. Fourier transform infrared spectroscopy (FTIR) and scanning electron microscopy (SEM) were also employed to evaluate the dentin remineralization induced by such ion-releasing resin composites. The null hypotheses tested were that there would be no difference between the 2 ion-releasing resins: 1) in the release of ICTP and CTX collagen fragments at 3 and $30 \mathrm{~d}$ and 2) in the remineralization of completely demineralized dentin after $30 \mathrm{~d}$ of artificial saliva (AS) storage.

\section{Materials and Methods}

\section{Preparation of Bioactive Glasses and lon-Releasing Composites}

A control resin co-monomer blend (RESIN) was formulated using 35 vol\% urethane-dimethacrylate, 6.6 vol\% bisphenolA-dimethacrylate, 30.4 vol\% triethylene-glycol-dimethacrylate (Esstech Essington), 15 vol\% 2-hydroxyethyl-methacrylate (HEMA; Sigma-Aldrich), 10 vol $\%$ absolute ethanol (Sigma-Aldrich), $0.5 \mathrm{wt} \%$ camphorquinone, and $1.0 \mathrm{wt} \%$ ethyl 4-dimethylaminobenzoate (Sigma-Aldrich).

Bioglass 45S5 was prepared by a high-temperature melting process as described by Sauro et al. (2013) (nominal composition: $46.1 \mathrm{~mol} \% \mathrm{SiO}_{2}, 26.9 \mathrm{~mol} \% \mathrm{CaO}, 24.4 \mathrm{~mol} \% \mathrm{Na}_{2} \mathrm{O}$, and $2.5 \mathrm{~mol} \% \mathrm{P}_{2} \mathrm{O}_{5}$ ). The experimental fluoride-containing bioactive glass (nominal composition: $42.7 \mathrm{~mol} \% \mathrm{SiO}, 26.2 \mathrm{~mol} \%$ $\mathrm{CaO}, 26.1 \mathrm{~mol} \% \mathrm{Na}_{2} \mathrm{O}, 4.0 \mathrm{~mol} \% \mathrm{P}_{2} \mathrm{O}_{5}$, and $1 \mathrm{~mol}^{2} \mathrm{CaF}_{2}$ ) was prepared as described previously (Groh et al. 2014). Glasses were milled and finally sieved $(<30 \mu \mathrm{m})$. They were incorporated with the resin control (filler/resin: 50/50 wt\%) to create an ion-releasing fluoride-free (BAG) and a fluoride-containing composite (BAG-F).

\section{Dentin Specimen Preparation}

Ten unerupted human third molars were used in accordance with the ethical guidelines of the research ethics committee and stored in $0.5 \mathrm{wt} \%$ chloramine-T/water solution at $4{ }^{\circ} \mathrm{C}$. Four beams $(5 \mathrm{~mm} \times 1 \mathrm{~mm} \times 1 \mathrm{~mm})$ were obtained from the mid-coronal dentin (total $=40)$ and randomly distributed into 4 different groups ( $n=10$ /group) to reduce the tooth-effect variability: 1) DENTIN, 2) RESIN, 3) BAG, and 4) BAG-F. All dentin beams were completely demineralized in $10 \%$ phosphoric acid for $12 \mathrm{~h}$ at $25^{\circ} \mathrm{C}(10 \mathrm{rpm})$. Absence of residual minerals was confirmed using digital radiography. The beams in group 1 were left completely demineralized and served as control, while the beams in groups 2, 3, and 4 were placed in direct contact (only on one side) with prepolymerized $\left(40 \mathrm{~s}, 1,200 \mathrm{~mW} / \mathrm{cm}^{2}\right.$; Radii Plus; SDI) resin beams (6 $\mathrm{mm} \times 3 \mathrm{~mm} \times 2 \mathrm{~mm}$ ) using orthodontics rubber bands.

\section{Assessment of Solubilized Telopeptides}

The dentin beam-resin assembly was immersed in individual propylene tubes containing $0.5 \mathrm{~mL} \mathrm{AS}(\mathrm{pH} 7.4)$ at $37^{\circ} \mathrm{C}$ for 3 or $30 \mathrm{~d}$. The AS consisted of $5 \mathrm{~mm}$ HEPES, $2.5 \mathrm{~mm} \mathrm{CaCl}$, $0.05 \mathrm{~mm} \mathrm{ZnCl}, 0.68 \mathrm{mmol} / \mathrm{L} \mathrm{KH}_{2} \mathrm{PO}_{4}, 30 \mathrm{mmol} / \mathrm{L} \mathrm{KCl}$, and $120 \mathrm{~mm} \mathrm{NaCl}$. After each incubation period, the medium of each specimen was collected and used to quantitate the solubilized collagen fragments.

MMP-mediated degradation was assessed by measuring the amount of solubilized ICTP using the UniQ EIA ELISA kit (Orion Diagnostica). Cathepsin $\mathrm{K}$-mediated collagen degradation was evaluated by measuring the amount of solubilized CTX using the Serum Cross Laps ELISA (Immunodiagnostic System).

ICTP and CTX release was calculated in each assay from a standard curve created using standards of known concentrations provided in the kit. Triplicate analysis was performed from each sample for each incubation period. Dentin beams were dried over anhydrous calcium sulfate for $8 \mathrm{~h}$, and the dry mass was then measured using a digital microbalance (Model MT5; Mettler Toledo) with a readability of $0.001 \mathrm{mg}$ and repeatability of $0.0008 \mathrm{mg}$. The $\mathrm{pH}$ of the incubation medium (AS) was also evaluated at 3 and $30 \mathrm{~d}$ of storage (Fig. 1).

The normality and equality of variance assumptions were statistically analyzed by Komolgorov-Smirnov normality test and modified Levine's test. Since the normality assumptions were not violated, the data were analyzed by 1-way analysis of variance (ANOVA) and post hoc multiple-comparisons Tukey's test ( $\alpha=0.05)$ (Sigma-Plot 11.5; Systat).

\section{FTIR Microspectroscopic Imaging and SEM Analysis}

The chemical mapping was performed on the specimens' surfaces before and after AS storage in contact with the composite blocks using a FTIR microspectroscopic system (Spectrum Spotlight FTIR imaging system; Perkin Elmer) with both single-point and imaging mapping mode. Specimens were scanned $\left(4,000\right.$ and $\left.650 \mathrm{~cm}^{-1}\right)$ at a $4-\mathrm{cm}^{-1}$ spectral resolution, with 2 scans per pixel. Image size was 80 to $40 \mu \mathrm{m}$, using a $6.25-\mu \mathrm{m}$ pixel resolution. An atmosphere correction was applied to the raw image to subtract the absorbance of water vapor and carbon dioxide. Images were elaborated using the "Spectrum Spotlight" software (Perkin Elmer). The amide I band and the $\mathrm{v}_{1} / \mathrm{v}_{3}$ PO domain between 1,200 and $900 \mathrm{~cm}^{-1}$ were used for image analysis. Finally, the specimens were mounted on aluminum stubs, dehydrated in silica gel, gold sputter-coated, and imaged by SEM (JSM-5600LV; JEOL), operating at $15 \mathrm{kV}$. 


\section{Three-Point Bending of Demineralized Dentin Beams}

A further 40 beams $(5 \mathrm{~mm} \times 1 \mathrm{~mm} \times$ $1 \mathrm{~mm}$ ) were prepared and distributed into different groups $(n=10 /$ group) as previously described. The stiffness of the wet specimens was assessed $\left(0.5 \mathrm{~mm} \mathrm{~min}^{-1}\right)$ using a 3-point bending testing device (Instron 3345; Instron Corp.) at time 0 and after $30 \mathrm{~d}$ of AS storage. The compressive force necessary to induce strain $(10 \%)$ in dentin beams was measured in a $1 \mathrm{~N}$ load cell; load was returned immediately to $0 \%$ stress to prevent creep of the demineralized collagen matrix. The modulus of elasticity of each specimen $\left(E^{\prime}\right)$ was calculated using the following equation: $\mathrm{E}=\mathrm{mL}^{3} / 4 \mathrm{bh}^{3}$, where $\mathrm{m}$ is the steepest slope along the linear portion of the load-displacement curve $(\mathrm{N} / \mathrm{mm}), L$ is the span length $(2.5 \mathrm{~mm}), \mathrm{b}$ is the width of test specimens $(1 \mathrm{~mm})$, and $\mathrm{h}$ is the thickness (1). $E^{\prime}$ was expressed in MPa. Since the distributions of data were not normally distributed, nonparametric tests were selected to analyze these variables. All data sets were submitted to Wilcoxon nonparametric and Mann-Whitney tests $(\alpha=0.05)$.

\section{Results}

The experimental BAG as well as

BAG-F resin showed an important alkalization potential at both 3 and $30 \mathrm{~d}$. By contrast, a neutral $\mathrm{pH}$ was observed for the incubation media of the groups RESIN and DENTIN (Fig. 1A). The specimens in contact with BAG showed a slight $\mathrm{E}^{\prime}$ reduction $(-3.7 \%)$, while the demineralized specimens stored alone (DENTIN: $-31.5 \%$ ) and those in contact with filler-free resin (RESIN: $-31.7 \%)$ showed the lowest moduli $(P<0.05)$ at $30 \mathrm{~d}$ (Fig. 1B). Conversely, the specimens in contact with BAG-F showed the highest $(P<0.05)$ increase in modulus of elasticity $(13.0 \%)$ at $30 \mathrm{~d}$. The release of CTX and ICTP telopeptide fragments at 3 and $30 \mathrm{~d}$ of AS incubation is shown in Figure 1-C1 and 1-C2, respectively. The demineralized specimens in contact with BAG showed CTX release both at $3 \mathrm{~d}(2.6 \pm 0.5 \mathrm{ng} / \mathrm{mg}$-dry-dentin $)$ and 30 $\mathrm{d}$ of AS storage $(0.9 \pm 0.2 \mathrm{ng} / \mathrm{mg}$-dry-dentin) significantly lower $(P<0.05)$ than the CTX fragments in groups DENTIN and RESIN (Fig. 1-C1). However, the specimens in contact with BAG-F showed the lowest $(P<0.05)$ CTX release both at $3 \mathrm{~d}(0.7 \pm 0.3 \mathrm{ng} / \mathrm{mg}$-dry-dentin $)$ and $30 \mathrm{~d}(0.6 \pm 0.1 \mathrm{ng} /$ mg-dry-dentin); no significant difference was observed at 30 $\mathrm{d}$ between BAG-F and BAG.

The demineralized specimens with the highest $(P<0.05)$ ICTP release after $3 \mathrm{~d}$ of storage were those in group DENTIN (36.5 $\pm 4.5 \mathrm{ng} / \mathrm{mg}$-dry-dentin), but there was no significant difference $(P>0.05)$ between the groups BAG, BAG-F, and RESIN (Fig. 1-C2). Conversely, the lowest $(P<0.05)$ ICTP release at $30 \mathrm{~d}$ was observed in group BAG-F $(39.6 \pm 5.7 \mathrm{ng} /$ mg-dry-dentin), followed $(P<0.05)$ by those in group BAG $(48.6 \pm 4.8 \mathrm{ng} / \mathrm{mg}$-dry-dentin). No significant difference $(P>$ 0.05 ) was found between the groups RESIN and DENTIN.

Specimens from all groups showed similar $(P>0.05)$ loss of dry mass (range, $-2 \%$ and $-4 \%$ ) at $3 \mathrm{~d}$ storage. After $30 \mathrm{~d}$ of incubation, there was a significant loss of dry mass $(P<0.05)$ in all groups compared to the results observed at $3 \mathrm{~d}$ of AS storage (range, $-12 \%$ and $-16 \%$ ), but again no significant difference $(P>0.05)$ was observed among the groups at $30 \mathrm{~d}$ of AS storage (Fig. 1C3).

The FTIR spectra showed that the specimens in contact with the filler-free resin showed no sign of remineralization, 
but only a noncrystallinity phase in the PO region at $1,014 \mathrm{~cm}^{-1}$ (Fig. 2A). Conversely, the specimens in contact with BAG or BAG-F for $30 \mathrm{~d}$ in AS showed precipitation of calcium phosphate $\left(1,100 \mathrm{~cm}^{-1}\right)$. This was also confirmed with the FTIR mapping-images; the 2 bioactive glass-doped resins were able to remineralize the dentin surface (Fig. 2B). Indeed, along with calcium phosphate $\left(1,100 \mathrm{~cm}^{-1}\right)$, it was also possible to detect orthophosphate $\left(1,038 \mathrm{~cm}^{-1}\right)$ and pyrophosphate $\left(746 \mathrm{~cm}^{-1}\right)$. Carbonate precipitation (range between, $1,120 \mathrm{~cm}^{-1}$ and 1,140 $\mathrm{cm}^{-1}$ ) was also detected on the surface of the specimens in contract with the bioactive composites. The SEM results (Fig. 3) showed that the resin BAG induced the precipitation of mineral crystals onto the surface and inside the dentin tubules (Fig. 3A, B). Similar mineralization was observed in the specimens in contact with BAG-F for $30 \mathrm{~d}$ in AS (Fig. 3C, D). Conversely, the specimens in contact with RESIN presented no clear remineralization but several patent dentin tubules with very few crystals deposited onto the dentin surface (Fig. 3E-H).

\section{Discussion}

Active endogenous proteases such as MMPs and cysteine cathepsins (e.g., cathepsin K) in demineralized dentin matrix (DM) are able to cleave the helical and telopeptide segments of the collagen matrix, resulting in a decrease of mechanical properties of dentin and longevity of restorations (Tjäderhane et al. 2013). The rationale for analyzing the specific C-terminal telopeptide fragments (e.g., ICTP and CTX) is to evaluate MMP- and cathepsin K-mediated degradation separately (Garnero et al. 2003; Tezvergil-Mutluay et al. 2014). TezvergilMutluay et al. (2013) reported that the release of ICTP fragments from DM is higher than CTX fragments; a similar trend was observed in the present study. This difference may be associated with the $\mathrm{pH}$ of the incubation media, as well as with the optimum $\mathrm{pH}$ activity of MMPs and cathepsin K (TezvergilMutluay et al. 2014). The $\mathrm{pH}$ of the incubation media where the DM specimens were stored alone or in contact with the filler-free resin was neutral (Fig. 1A); these groups showed the greatest CTX and ICTP release after $30 \mathrm{~d}$ of AS storage. Holman et al. (1999) reported that the optimum $\mathrm{pH}$ for several MMPs to function at near-maximum rates is between 7.2 and 7.5. To degrade telopeptides at same rate of MMPs, cathepsin $\mathrm{K}$ should work at pH 5.5 (Marini et al. 2000). However, at neutral $\mathrm{pH}$, cathepsin $\mathrm{K}$ is still able to accomplish its catalytic activity at lower rates (Kometani et al. 2010).

The experimental bioactive composites tested in this study (BAG and BAG-F) were able to alkalinize the incubation media (Fig. 1A). The DM specimens in these 2 groups presented CTX and ICTP release significantly lower compared to RESIN and DENTIN. BAG-F induced greater CTP inhibition at $3 \mathrm{~d}$ and MMP inhibition at $30 \mathrm{~d}$ of AS storage compared to BAG $(P<0.05)$. This is somewhat in contrast with the previous findings, which showed a collagen degradation zone in contact with strong alkaline materials such as calcium silicate cements (Atmeh et al. 2012; Leiendecker et al. 2012). Conversely, resin-based materials doped with bioactive fillers such as Bioglass $45 \mathrm{~S} 5$ have been shown to preserve the integrity of collagen fibrils within the hybrid layer even after prolonged storage in simulated body fluids (Profeta et al. 2012).

The ICTP results obtained with the DM specimens stored in contact with BAG are in accordance with previous studies (Osorio et al. 2012; Tezvergil-Mutluay et al. 2014), with the only difference that the specimens in this study were not infiltrated with the tested resins, but only one side of the DM specimens was placed in direct contact with prepolymerized resin beams. The rationale behind employing such an approach was to avoid possible interference with the diffusion of ICTP and CTX telopeptide fragments by the resin monomers that infiltrated the demineralized collagen matrices. Comparing the results attained in this study to those presented by Osorio et al. (2012) and Tezvergil-Mutluay et al. (2014), it is possible to affirm that both experimental methods may be considered valid for the assessment of ICTP and CTX. Conversely, the results of dry mass loss obtained in this study were not in accordance with those reported by Tezvergil-Mutluay et al. (2014). Such a difference may be attributed to the fact that the DM specimens in the present study were not totally resin infiltrated. Indeed, we hypothesize that such an experimental design may have been responsible for the lack of significant differences among the groups, as only one side of the DM specimens was protected by the bioactivity of the experimental BAG-F and BAG, which may have inhibited MMPs and CTPs at the resin-dentin interface. Moreover, it is well known that bioactive resin-based bioactive glass-containing materials are able to release $\left(\mathrm{Ca}^{2+}\right)$ and $\left(\mathrm{PO}_{4}{ }^{3-}\right)$ ions, which reprecipitate as apatite-like crystallites (Sauro et al. 2013). Such mineral precipitation may have occurred within collagen fibrils without forming excessive mineral clusters and thus without increasing the dry mass of the specimens after prolonged incubation. This latter hypothesis about remineralization of collagen fibrils requires further investigation.

However, it is also important to consider that the presence of bioactive glasses within resin-dentin interfaces may induce the release of a hydrated silica $\mathrm{Si}(\mathrm{OH})_{4}$, which then binds nonspecifically to demineralized collagen fibrils and polymerizes into a porous $\mathrm{SiO}$-rich layer. Such a layer might serve as a template for precipitation of amorphous calcium phosphate (Hench and Wilson 1993; Sauro and Pashley 2016), which subsequently converts into biomimetic nonstoichiometric apatite in an alkaline environment (Hoppe et al. 2011). This latter environment is attained through a rapid exchange of sodium $\left(\mathrm{Na}^{+}\right)$and hydrogen ions $\left(\mathrm{H}^{+}\right)$or hydronium ion $\left(\mathrm{H}_{3} \mathrm{O}^{-}\right)$; such an alkaline $\mathrm{pH}$, along with $\mathrm{Si}(\mathrm{OH})_{4}$ condensation and precipitation of $\mathrm{Ca}^{2+}$ and $\mathrm{PO}_{4}{ }^{3-}$ ions, contributes to fossilize proteolytic enzymes, thereby reducing their degradation activity (Tjäderhane et al. 2013). Makowski and Ramsby (2004) showed that mineral precipitation and apatite crystallization might immobilize proteases through the formation of $[\mathrm{Ca} / \mathrm{PO}-\mathrm{MMP}]$ complexes.

The BAG-F resin showed greater ability than BAG in increasing the stiffness of the demineralized dentin specimens. These results were also supported by FTIR (Fig. 2) and SEM results (Fig. 3). Fluoride-containing bioactive glasses are well known to release fluoride ions into solution (Brauer et al. 2010). 
Moreover, the fluoride-containing bioactive glass used in this study has higher phosphate content compared with Bioglass 45S5. Both elements are known to accelerate apatite formation maintaining the same network connectivity (i.e., the same polymerization of the silicate network) of Bioglass 45S5 (Mneimne et al. 2011). Therefore, we assume that the release of fluoride ions and the greater bioactivity of such an innovative bioglass incorporated in BAG-F resin may have contributed to attaining such better results.

It has been advocated that fluoride might inhibit both pro- and active forms of MMP-2 and MMP-9 from human saliva Kato et al. (2014). Brackett et al. (2015) showed that $150 \mathrm{ppm} \mathrm{NaF}$ could inhibit both soluble and matrixbound MMP-2, MMP-8, and MMP-9. Moreover, these authors hypothesized that 75 to $600 \mathrm{ppm}$ fluoride could complex not only with ionized calcium bound to the enzyme but also with $\mathrm{Ca}^{2+}$ in the incubation medium to form tightly complexed $\mathrm{CaF}_{2}$. Therefore, fluoride may have chelated $\mathrm{Ca}^{2+}$ and $\mathrm{Zn}^{2+}$ to inactivate MMPs; MMPs depend on calcium to maintain their 3-dimensional configuration for enzymatic activity (Thompson et al. 2012).

Furthermore, fluoride has been demonstrated to be effective in inhibiting human recombinant cathepsin $\mathrm{K}$ and $\mathrm{B}$ (Mei et al. 2014). Brackett et al. (2015) stated that since EDTA does not inhibit cathepsin activity, fluoride ions may not inhibit dentin matrix cathepsin activity via a chelating approach. We believe that there may be a chemical interaction between cathepsin $\mathrm{K}$ and fluoride, which caused alteration of the 3-dimensional configuration as well as its ability to bind and cleave telopeptides in a specific zone of the collagen fibril. However, the mechanism of inhibition of fluoride on cathepsin $\mathrm{K}$ is still unclear, and this should be further investigated in future studies.

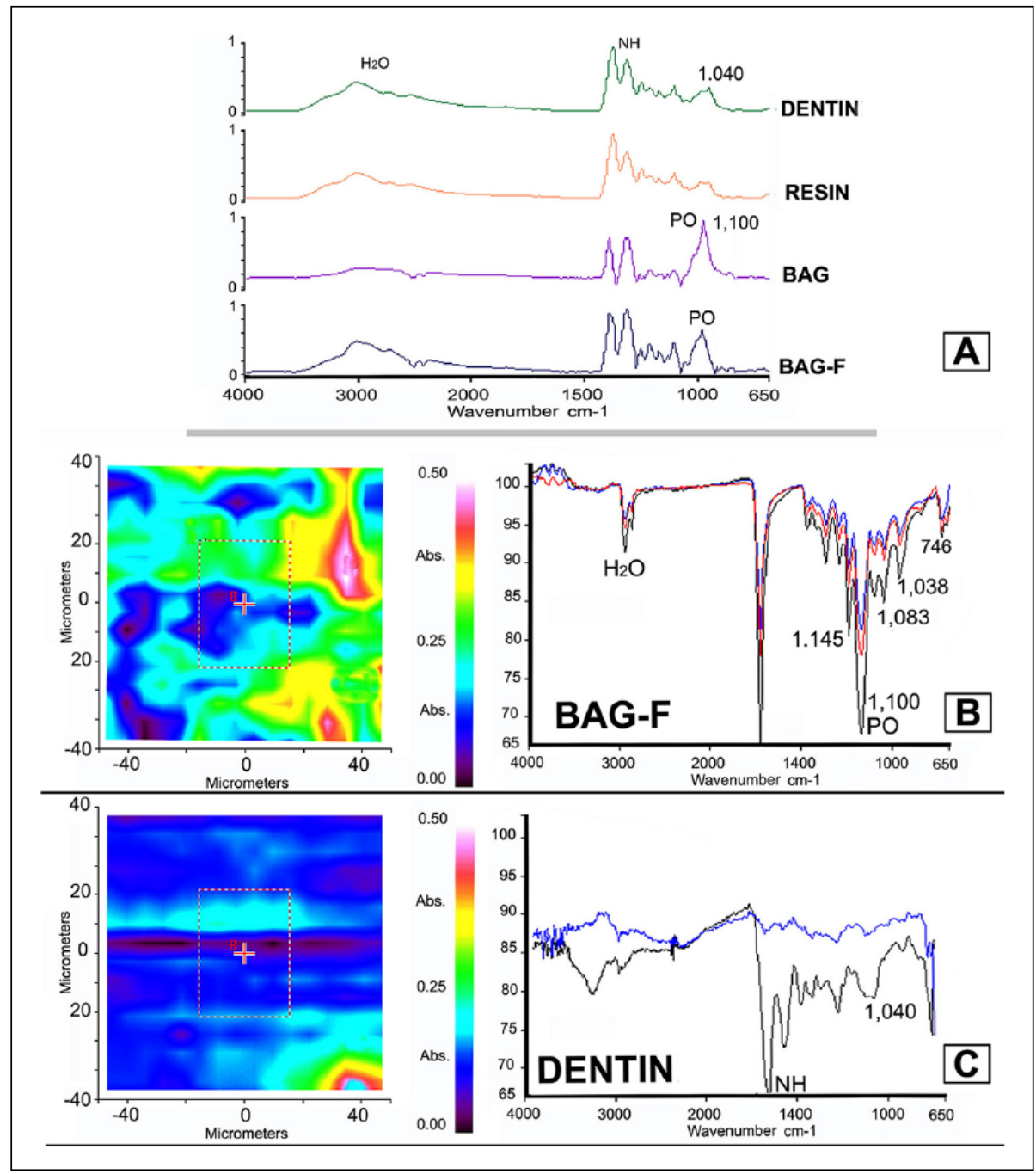

Figure 2. Fourier transform infrared spectroscopy (FTIR) of dentine remineralization induced by the 2 bioactive composites. (A) FTIR specta $\left(650\right.$ to $\left.4,000 \mathrm{~cm}^{-1}\right)$ of the demineralized dentin matrix (DENTIN) and dentin matrices in contact with the filler-free resin (RESIN) after $30 \mathrm{~d}$ of storage in artificial saliva (AS). These spectra represented the average of 3 single scanning analyses that were then processed by smoothing, baseline correction, and normalization to the amide I peak. FTIR spectra showed mainly the absorption band of collagen at I,650 cm (amide I), $1,550 \mathrm{~cm}^{-1}$ (amide II), I,450 cm and water $\left(\mathrm{O}-\mathrm{H}: 2,800\right.$ to $\left.3,100 \mathrm{~cm}^{-1}\right)$. The absorption band at $\mathrm{I}, 0 \mathrm{I} 4 \mathrm{~cm}^{-1}$ indicates a noncrystallinity phase in the PO region. The FTIR spectra of the demineralized dentin matrix in contact for $30 \mathrm{~d}$ in AS with the BAG resin or BAG-F resin show an intense band at $1,100 \mathrm{~cm}^{-1}$, which is associated with the inorganic PO component. (B) Representative FTIR image $(80 \times 80 \mu \mathrm{m})$ and relative spectra of a specimen of demineralized dentin matrix in contact for $30 \mathrm{~d}$ in AS with the resin containing the fluoridedoped bioglass (BAG-F). It is possible to note the remineralization effect of such a bioactive resin on the entire dentin surface. The most prominent absorption band at $\mathrm{I}, 100 \mathrm{~cm}^{-1}$ is associated with the inorganic PO component, along with an intense band at $1,650 \mathrm{~cm}^{-1}$ from the collagen. Orthophosphate optical absorption band $\left(I, 038 \mathrm{~cm}^{-1}\right.$ ) and absorption bands at I,083 cm-1 (orthophosphate stretching vibrations- $v 3$ ) are also clearly visible. It is also possible to observe carbonate stretching vibrations between $I, I 20 \mathrm{~cm}^{-1}$ and $I, 140 \mathrm{~cm}^{-1}$ and OPO stretching of pyrophosphates at $746 \mathrm{~cm}^{-1}$. (C) Representative FTIR image and relative spectra of a specimen of demineralized dentin matrix immersed in AS for $30 \mathrm{~d}$. It is possible to note no clear dentin remineralization as the main absorption bands are those of demineralized collagen $\left(I, 650 \mathrm{~cm}^{-1}\right.$ and $\left.I, 550 \mathrm{~cm}^{-1}\right)$ and $\mathrm{I}, 014 \mathrm{~cm}^{-1}$, which indicates very little phosphate uptake (mineral precipitation) in dentin.

Considering the results obtained in this study, we need to partially reject the first null hypothesis as the experimental fluoridecontaining phosphate-rich bioactive glass incorporated into a 


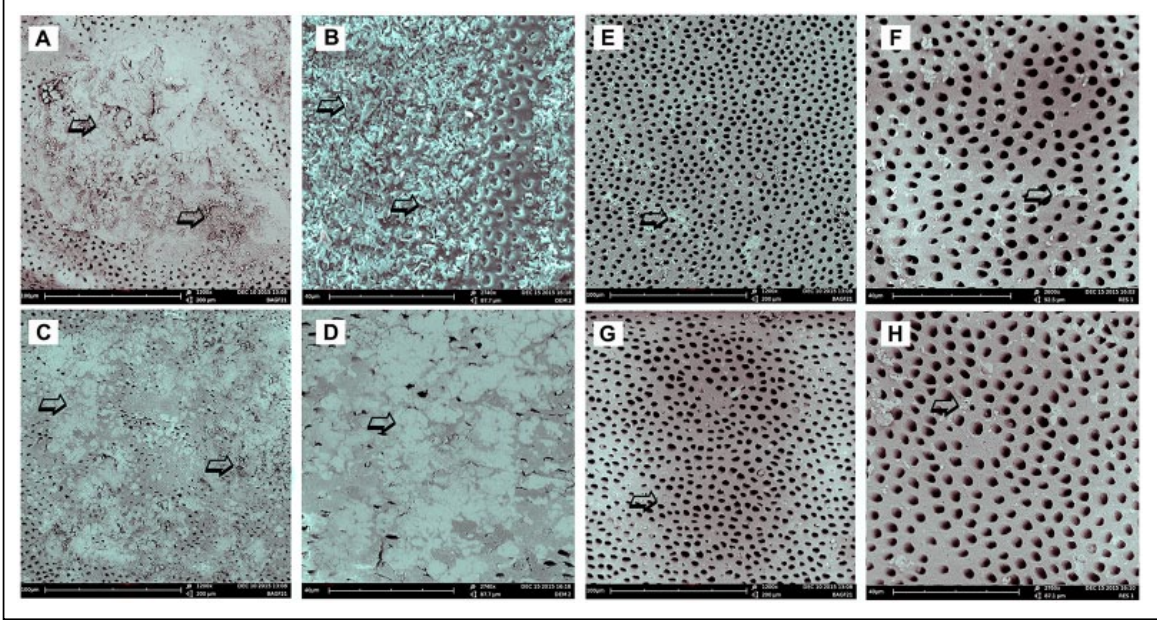

Figure 3. Scanning electron microscopy of dentine remineralization induced by the 2 bioactive composites. (A) Representative SEM micrograph of a specimen of demineralized dentin in contact for $30 \mathrm{~d}$ in artificial saliva (AS) with the resin containing bioglass fillers (BAG) where it is possible to observe a clear mineral precipitation (arrows) induced by the bioactive material onto the dentin surface. At higher magnification (B), crystals deposited onto the dentin surface and inside the dentin tubules can be clearly observed (arrows). (C) Representative SEM micrograph of a specimen of demineralized dentin in contact for $30 \mathrm{~d}$ in AS with the resin containing fluoride-bioglass fillers (BAG-F). Also in this case, it is easy to observe a clear mineral precipitation (arrows) induced by this ion-releasing material on the dentin surface. At higher magnification (D), the dentin surface and the dentin tubules appear clearly remineralized (arrows). (E) Representative SEM micrograph of a specimen of demineralized dentin in contact with the filler-free resin control (RESIN) for $30 \mathrm{~d}$ in AS where it is possible to note a dentin surface with no clear mineral precipitation (arrows). At higher magnification (F), several patent dentin tubules can be seen along with very few crystals deposited onto the dentin surface (arrows). (G) The demineralized dentin immersed (DENTIN) for $30 \mathrm{~d}$ shows a demineralized dentin surface with several patent dentin tubules (arrows) and $(\mathbf{H})$ very few crystals deposited onto the dentin surface (arrows).

resin-based dental composite showed greater impairment of the degradation activity of CTP at $3 \mathrm{~d}$ and MMPs at $30 \mathrm{~d}$ of AS storage. Conversely, the second null hypothesis must be rejected as the resin containing the fluoride-containing phosphate-rich bioactive glass had greater ability than the resin containing Bioglass 45S5 in remineralizing the demineralized dentin matrices after prolonged AS storage.

In conclusion, we canassume the fluoride-containing phosphate-rich bioactive micro-filler incorporated into resin-based composites is more bioactive than BAG $45 \mathrm{~S} 5$. This may be due to the release of fluoride ions, as well as to the greater amount of phosphates, which accelerate dentin remineralization as well as fossilization/inhibition of both MMPs and CTPs. Moreover, since Altinci et al. (2016) demonstrated that it was possible to inhibit matrix-bound cathepsin-mediated dentin matrix degradation by using a minimum concentration of $\mathrm{NaF}(\geq 120 \mathrm{~mm})$, we hypothesize that the fluoride/phosphate-rich bioactive glass used in this study might also have a direct inhibition effect on CTP-mediated degradation related to its ability to release fluoride ions during early contact with biological fluids (e.g., $3 \mathrm{~d}$ in AS) (Brauer et al. 2010).

\section{References} 91(5):454-459. 6(8):3275-3282.

\section{Author Contributions}

A. Tezvergil-Mutluay, D.S. Brauer, S. Sauro, contributed to conception, design, data acquisition, analysis, and interpretation, drafted and critically revised the manuscript; R. SeseogullariDirihan, contributed to conception, design, data analysis, and interpretation, drafted and critically revised the manuscript; V.P. Feitosa, contributed to conception, design, data acquisition, and analysis, drafted and critically revised the manuscript; G. Cama, contributed to design and data acquisition, drafted and critically revised the manuscript. All authors gave final approval and agree to be accountable for all aspects of the work.

\section{Acknowledgments}

This work was supported by the research grant INDI16/34 and INDI1527B, Programa de Consolidación de Indicadores: Fomento Plan Estatal CEU-UCH 2014-2017 to S.S. (principal investigator $[\mathrm{PI}])$. This study was also supported by grant 8126472 from the Academy of Finland to A.T.-M. (PI) and EVO funding of Turku University Hospital to A.T.-M. (PI). The authors declare no potential conflicts of interest with respect to the authorship and/or publication of this article.

Abuna G, Feitosa VP, Correr AB, Cama G, Giannini M, Sinhoreti MA, Pashley DH, Sauro S. 2016. Bonding performance of experimental bioactive/biomimetic self-etch adhesives doped with calcium-phosphate fillers and biomimetic analogs of phosphoproteins. J Dent. 52:79-86.

Aguiar TR, Vidal CM, Phansalkar RS, Todorova I, Napolitano JG, McAlpine JB, Chen SN, Pauli GF, Bedran-Russo AK. 2014. Dentin biomodification potential depends on polyphenol source. J Dent Res. 93(4):417-422.

Altinci P, Mutluay M, Seseogullari-Dirihan R, Pashley D, Tjäderhane L, Tezvergil-Mutluay A. 2016. NaF inhibits matrix-bound cathepsin-mediated dentin matrix degradation. Caries Res. 50(2):124-132.

Atmeh AR, Chong EZ, Richard G, Festy F, Watson TF. 2012. Dentin-cement interfacial interaction: calcium silicates and polyalkenoates. J Dent Res.

Brackett MG, Agee KA, Brackett WW, Key WO, Sabatini C, Kato MT, Buzalaf MA, Tjäderhane L, Pashley DH. 2015. Effect of sodium fluoride on the endogenous MMP activity of dentin matrices. J Nat Sci. 1(6):pii:e118.

Brauer DS, Karpukhina N, O'Donnell MD, Law RV, Hill RG. 2010. Fluoridecontaining bioactive glasses: effect of glass design and structure on degradation, $\mathrm{pH}$ and apatite formation in simulated body fluid. Acta Biomater.

De Munck J, Van den Steen PE, Mine A, Van Landuyt KL, Poitevin A, Opdenakker G, Van Meerbeek B. 2009. Inhibition of enzymatic degradation of adhesive-dentin interfaces. J Dent Res. 88(12):1101-1106.

DeVito-Moraes AG, Francci C, Vidal CM, Scaffa PM, Nesadal D, Yamasaki LC, Nicolau J, Nascimento FD, Pashley DH, Carrilho MR. 2016. Phosphoric acid concentration affects dentinal MMPs activity. J Dent. 53:30-37. 
Garnero P, Ferreras M, Karsdal MA, Nicamhlaoibh R, Risteli J, Borel O, Qvist P, Delmas PD, Foged NT, Delaissé JM. 2003. The type I collagen fragments ICTP and CTX reveal distinct enzymatic pathways of bone collagen degradation. J Bone Miner Res. 18(5):859-867.

Groh D, Döhler F, Brauer DS. 2014. Bioactive glasses with improved processing. Part 1. Thermal properties, ion release and apatite formation. Acta Biomater. 10(10):4465-4473.

Hench LL, Wilson J. 1993. Introduction. In: Hench LL, Wilson J, editors. An introduction to bioceramics. Singapore: World Scientific Publishing Co. Pte. Ltd. p. 1-24.

Holman CM, Kan CC, Gehring MR, Van Wart HE. 1999. Role of His-224 in the anomalous $\mathrm{pH}$ dependence of human stromelysin-1. Biochemistry. 38(2):677-681.

Hoppe A, Güldal NR, Boccaccini AR. 2011. A review of the biological response to ionic dissolution products from bioactive glasses and glass-ceramics. Biomaterials. 32(11):2757-2774.

Kato MT, Bolanho A, Zarella BL, Salo T, Tjäderhane L, Buzalaf MA. 2014. Sodium fluoride inhibits MMP-2 and MMP-9. J Dent Res. 93(1):74-77.

Kometani M, Nonomura K, Tomoo T, Niwa S. 2010. Hurdles in the drug discovery of cathepsin K inhibitors. Curr Top Med Chem. 10(7):733-744.

Lehmann N, Debret R, Roméas A, Magloire H, Degrange M, Bleicher F, Sommer P, Seux D. 2009. Self-etching increases matrix metalloproteinase expression in the dentin-pulp complex. J Dent Res. 88(1):77-82.

Leiendecker AP, Qi YP, Sawyer AN, Niu LN, Agee KA, Loushine RJ, Weller RN, Pashley DH, Tay FR. 2012. Effects of calcium silicate-based materials on collagen matrix integrity of mineralized dentin. J Endod. 38(6):829-833.

Makowski GS, Ramsby ML. 2004. Differential effect of calcium phosphate and calcium pyrophosphate on binding of matrix metalloproteinases to fibrin: comparison to a fibrin-binding protease from inflammatory joint fluids. Clin Exp Immunol. 136(1):176-187.

Marini S, Fasciglione GF, de Sanctis G, D'Alessio S, Politi V, Coletta M. 2000. Cleavage of bovine collagen I by neutrophil collagenase MMP-8. Effect of $\mathrm{pH}$ on the catalytic properties as compared to synthetic substrates. J Biol Chem. 275(25):18657-18663.

Mei ML, Ito L, Cao Y, Li QL, Chu CH, Lo EC. 2014. The inhibitory effects of silver diamine fluorides on cysteine cathepsins. J Dent. 42(3):329-335.

Mneimne M, Hill RG, Bushby AJ, Brauer DS. 2011. High phosphate content significantly increases apatite formation of fluoride-containing bioactive glasses. Acta Biomater. 7(4):1827-1834.

Nascimento FD, Minciotti CL, Geraldeli S, Carrilho MR, Pashley DH, Tay FR, Nader HB, Salo T, Tjäderhane L, Tersariol ILS. 2011. Cysteine cathepsins in human carious dentin. J Dent Res. 90(4):506-511.

O’Donnell MD, Watts SJ, Hill RG, Law RV. 2009. The effect of phosphate content on the bioactivity of soda-lime-phosphosilicate glasses. J Mater Sci Mater Med. 20(8):1611-1618.
Osorio R, Yamauti M, Sauro S, Watson TF, Toledano M. 2012. Experimental resin cements containing bioactive fillers reduce matrix metalloproteinasemediated dentin collagen degradation. J Endod. 38(9):1227-1232.

Palosaari H, Pennington CJ, Larmas M, Edwards DR, Tjäderhane L, Salo T. 2003. Expression profile of matrix metalloproteinases (MMPs) and tissue inhibitors of MMPs in mature human odontoblasts and pulp tissue. Eur J Oral Sci. 111(2):117-127.

Pashley DH, Tay FR, Breschi L, Tjäderhane L, Carvalho RM, Carrilho M, Tezvergil-Mutluay A. 2011. State of the art etch-and-rinse adhesives. Dent Mater. 27(1):1-16.

Pashley DH, Tay FR, Yiu C, Hashimoto M, Breschi L, Carvalho RM, Ito S. 2004. Collagen degradation by host-derived enzymes during aging. J Dent Res. 83(3):216-221.

Profeta AC, Mannocci F, Foxton RM, Thompson I, Watson TF, Sauro S. 2012. Bioactive effects of a calcium/sodium phosphosilicate on the resin-dentine interface: a microtensile bond strength, scanning electron microscopy, and confocal microscopy study. Eur J Oral Sci. 120(4):353-362.

Sauro S, Osorio R, Fulgencio R, Watson TF, Cama G, Thompson I, Toledano M. 2013. Remineralisation properties of innovative light-curable resinbased dental materials containing bioactive micro-fillers. J Mater Chem B. 20(1):2624-2638

Sauro S, Osorio R, Watson TF, Toledano M. 2012. Therapeutic effects of novel resin bonding systems containing bioactive glasses on mineraldepleted areas within the bonded-dentine interface. J Mater Sci Mater Med. 23(6):1521-1532.

Sauro S, Pashley DH. 2016. Strategies to stabilise dentine-bonded interfaces through remineralising operative approaches - state of the art. Int J Adhes Adhes 69:39-57.

Tezvergil-Mutluay A, Mutluay M, Seseogullari-Dirihan R, Agee KA, Key WO, Scheffel DL, Breschi L, Mazzoni A, Tjäderhane L, Nishitani Y, et al. 2013. Effect of phosphoric acid on the degradation of human dentin matrix. J Dent Res. 92(1):87-91.

Tezvergil-Mutluay A, Seseogullari-Dirihan R, Feitosa VP, Tay FR, Watson TF, Pashley DH, Sauro S. 2014. Zoledronate and ion-releasing resins impair dentin collagen degradation. J Dent Res. 93(10):999-1004

Thompson JM, Agee K, Sidow SJ, McNally K, Lindsey K, Borke J, Elsalanty M, Tay FR, Pashley DH. 2012. Inhibition of endogenous dentin matrix metalloproteinases by ethylenediaminetetraacetic acid. J Endod. $38(1): 62-65$

Tjäderhane L, Nascimento FD, Breschi L, Mazzoni A, Tersariol IL, Geraldeli S, Tezvergil-Mutluay A, Carrilho MR, Carvalho RM, Tay FR, et al. 2013. Optimizing dentin bond durability: control of collagen degradation by matrix metalloproteinases and cysteine cathepsins. Dent Mater. 29(1): $116-135$ 